\title{
Article \\ Phytochemical-Assisted Green Synthesis of Nickel Oxide Nanoparticles for Application as Electrocatalysts in Oxygen Evolution Reaction
}

\author{
Vidhya Selvanathan ${ }^{1}$, M. Shahinuzzaman ${ }^{2, * 10}$, Shankary Selvanathan ${ }^{3}$, Dilip Kumar Sarkar ${ }^{1}$, Norah Algethami ${ }^{4}$, \\ Hend I. Alkhammash ${ }^{5}$, Farah Hannan Anuar ${ }^{6}$ (D), Zalita Zainuddin ${ }^{7}$, Mohammod Aminuzzaman ${ }^{8,9}$, \\ Huda Abdullah ${ }^{10}$ and Md. Akhtaruzzaman ${ }^{1, *(D)}$
}

1 Solar Energy Research Institute (SERI), Universiti Kebangsaan Malaysia (UKM), Bangi 43600, Selangor, Malaysia; vidhya@ukm.edu.my (V.S.); dilipks551@gmail.com (D.K.S.)

2 School of Computer Science and Information Technology, Central University of Science and Technology, Dhaka 1216, Bangladesh

3 Department of Chemistry, Faculty of Science, University of Malaya, Kuala Lumpur 50603, Malaysia; shankaryselvanathan@gmail.com

4 Department of Physics, Faculty of Science, Taif University, Taif 21944, Saudi Arabia; n.alkthamy@tu.edu.sa

5 Department of Electrical Engineering, College of Engineering, Taif University, Taif 21944, Saudi Arabia; Khamash.h@tu.edu.sa

check for

updates

Citation: Selvanathan, V.;

Shahinuzzaman, M.; Selvanathan, S.; Sarkar, D.K.; Algethami, N.; Alkhammash, H.I.; Anuar, F.H.; Zainuddin, Z.; Aminuzzaman, M.; Abdullah, H.; et al. Phytochemical -Assisted Green Synthesis of Nickel Oxide Nanoparticles for Application as Electrocatalysts in Oxygen Evolution Reaction. Catalysts 2021, 11, 1523. https://doi.org/10.3390/ catal11121523

Academic Editors: Stéphanie Lambert and Julien Mahy

Received: 20 November 2021 Accepted: 11 December 2021 Published: 15 December 2021

Publisher's Note: MDPI stays neutral with regard to jurisdictional claims in published maps and institutional affiliations.

Copyright: (c) 2021 by the authors. Licensee MDPI, Basel, Switzerland. This article is an open access article distributed under the terms and conditions of the Creative Commons Attribution (CC BY) license (https:// creativecommons.org/licenses/by/ $4.0 /)$.
6 Department of Chemistry, Faculty of Science and Technology, Universiti Kebangsaan Malaysia (UKM), Bangi 43600, Selangor, Malaysia; farahhannan@ukm.edu.my

7 Department of Physics, Faculty of Science and Technology, Universiti Kebangsaan Malaysia (UKM), Bangi 43600, Selangor, Malaysia; zazai@ukm.edu.my

8 Department of Chemical Science, Faculty of Science, Universiti Tunku Abdul Rahman (UTAR), Perak Campus, Jalan Universiti, Bandar Barat, Kampar 31900, Perak, Malaysia; mohammoda@utar.edu.my

9 Centre for Photonics and Advanced Materials Research (CPAMR), Universiti Tunku Abdul Rahman (UTAR), Jalan Sungai Long, Bandar Sungai Long, Kajang 43000, Selangor, Malaysia

10 Department of Electrical, Electronic \& Systems Engineering, Faculty of Engineering \& Built Environment, Universiti Kebangsaan Malaysia (UKM), Bangi 43600, Selangor, Malaysia; huda.abdullah@ukm.edu.my

* Correspondence: shahinchmiu@gmail.com (M.S.); akhtar@ukm.edu.my (M.A.); Tel.: +603-89118587 (M.S. \& M.A.)

Abstract: Electrocatalytic water splitting is a promising solution to resolve the global energy crisis. Tuning the morphology and particle size is a crucial aspect in designing a highly efficient nanomaterials-based electrocatalyst for water splitting. Herein, green synthesis of nickel oxide nanoparticles using phytochemicals from three different sources was employed to synthesize nickel oxide nanoparticles $\left(\mathrm{NiO}_{\mathrm{x}} \mathrm{NPs}\right)$. Nickel (II) acetate tetrahydrate was reacted in presence of aloe vera leaves extract, papaya peel extract and dragon fruit peel extract, respectively, and the physicochemical properties of the biosynthesized NPs were compared to sodium hydroxide $(\mathrm{NaOH})$-mediated $\mathrm{NiO}_{\mathrm{x}}$. Based on the average particle size calculation from Scherrer's equation, using $X$-ray diffractograms and field-emission scanning electron microscope analysis revealed that all three biosynthesized $\mathrm{NiO}_{\mathrm{x}}$ NPs have smaller particle size than that synthesized using the base. Aloe-vera-mediated $\mathrm{NiO}_{x} \mathrm{NPs}$ exhibited the best electrocatalytic performance with an overpotential of $413 \mathrm{mV}$ at $10 \mathrm{~mA} \mathrm{~cm}^{-2}$ and a Tafel slope of $95 \mathrm{mV} \mathrm{dec}^{-1}$. Electrochemical surface area (ECSA) measurement and electrochemical impedance spectroscopic analysis verified that the high surface area, efficient charge-transfer kinetics and higher conductivity of aloe-vera-mediated $\mathrm{NiO}_{x} \mathrm{NPs}$ contribute to its low overpotential values.

Keywords: green synthesis; nickel oxide; nanoparticles; oxygen evolution reaction; electrocatalysts

\section{Introduction}

One of the greatest challenges of the technological era is the inflating global energy demand as electricity becomes a necessity in every facet of life. The non-renewable nature of fossil-fuel-based energy production has stimulated the pursuit of sustainable energy 
sources such as solar and wind energy. To overcome the intermittency issues of these renewable energy sources, production of hydrogen fuel from electrocatalytic water splitting is considered a strategic approach. Under a standard environment, $1.23 \mathrm{~V}$ of thermodynamic potential is required to drive electrochemical water splitting [1]. Nonetheless, in practical conditions, the sluggish kinetics of oxygen evolution reaction (OER) mandates high overpotential to generate the required current density. Hence, most practical electrolyzers consume more than $1.23 \mathrm{~V}$ to drive the desired reaction.

Electrocatalysts are usually employed to attain satisfactory water-splitting efficiency, but by far best electrocatalytic performance was demonstrated by noble-metal-based materials (e.g., $\mathrm{RuO}_{2}$ and $\mathrm{IrO}_{2}$ ). The high cost and low abundancy of noble metals are not conducive for large-scale water-splitting applications. Therefore, non-precious transition metal oxides and hydroxides were explored as alternative electrocatalysts. Nickel oxide $\left(\mathrm{NiO}_{\mathrm{x}}\right)$ is one such promising material for electrocatalytic water splitting due to its high electron transport capacity, good chemical stability and facile method of synthesis. Particularly, in the case of $\mathrm{NiO}_{x} \mathrm{NPs}$, the synthetic route adapted influences the electrical and structural properties of the material.

Traditionally, metal oxide nanoparticles are synthesized using a strong base as a reducing agent, followed by reaction with a capping agent or reducing agent. Sometimes, additional organic solvents are required to dissolve these capping agents. Alternatively, a green synthesis approach can be utilized to reduce the usage of unnecessary toxic chemicals [2]. In green synthesis, primary and secondary metabolites of plants are used to aid the synthesis of metal oxide nanoparticles [3]. These metabolites form a coating layer or stabilizing layer on the surface of the metal oxide nanoparticles and prevent intensive aggregation, thus yielding well-defined morphologies and tunable particle size [4]. The choice of plant species and its respective parts play an important role in determining the morphology and particle size of the NPs as they contain distinct phytochemical profiles [5].

One of the major advantages of chemical capping agents is the tunability of the species to yield nanoparticles with different particle size and morphology. For example, in the case of synthetic-polymers-based capping agents, factors such as the nature of polymer (functional group, branching), molecular weight and concentration were found to affect its function as a stabilizer [6]. However, in the context of green synthesis, much work is dedicated to exploring the effect of using a single plant extract formulation. Since each plant species comes with its unique cocktail of phytochemicals, it is useful to compare the effect of using different plant extracts on the overall size and morphology of the nanoparticles. Thus, in this study we have explored three different plant extracts, namely, aloe vera leaves extract, papaya fruit peel extract and dragon fruit peel extract, as capping agents for $\mathrm{NiO}_{x}$ NPs.

Aloe vera gel contains mostly water and polysaccharides, such as pectins, cellulose, hemicellulose, glucomannan and acemannan $[7,8]$. In addition to that, the aloe latex is made up of hydroxyanthracenic derivatives and anthraquinone glycosides, along with emodin. Papaya peel is rich in a variety of vitamins including $\beta$-carotene, vitamin B (thiamine, riboflavin, niacin and folate), vitamin $C$ and vitamin $E$ [9]. On the other hand, dragon fruit peel is reported to contain wide compositions of antioxidants such as betasianin, flavonoids, phenols, terpenoids, thiamine, niacin, pyridoxine and cobalamin [10]. The effect of these different phytochemical compositions of extracts on the structural and morphological properties of the $\mathrm{NiO}_{x} \mathrm{NPs}$ and, consequently, their electrocatalytic activities for OER were studied and reported in detail.

\section{Results and Discussion}

\subsection{Structural Properties}

Figure 1 shows the structural properties of the synthesized $\mathrm{NiO}_{x}$ nanoparticles using different extracts after calcination at $300{ }^{\circ} \mathrm{C}$ and $600{ }^{\circ} \mathrm{C}$. As shown in the diffractograms, all the samples exhibited diffraction peaks at $2 \theta$ values of $37.2,43.2,62.8,75.4$ and $79.4^{\circ}$ attributed to (101), (012), (104), (113) and (006) crystal planes of cubic $\mathrm{NiO}_{x}[11,12]$. These 
peaks were in agreement with the standard JCPDS card no. 00-004-1159. Significant differences in the peak intensities were evident between samples calcined at $300{ }^{\circ} \mathrm{C}$ and $600{ }^{\circ} \mathrm{C}$. At lower calcination temperature, the presence of organic residues from the plant extract used during $\mathrm{NiO}_{x}$ synthesis reduced the crystallinity of the nanoparticles. Upon calcination at $600{ }^{\circ} \mathrm{C}$, high purity $\mathrm{NiO}_{x}$ nanoparticles were produced, leading to sharp and intense XRD peaks.

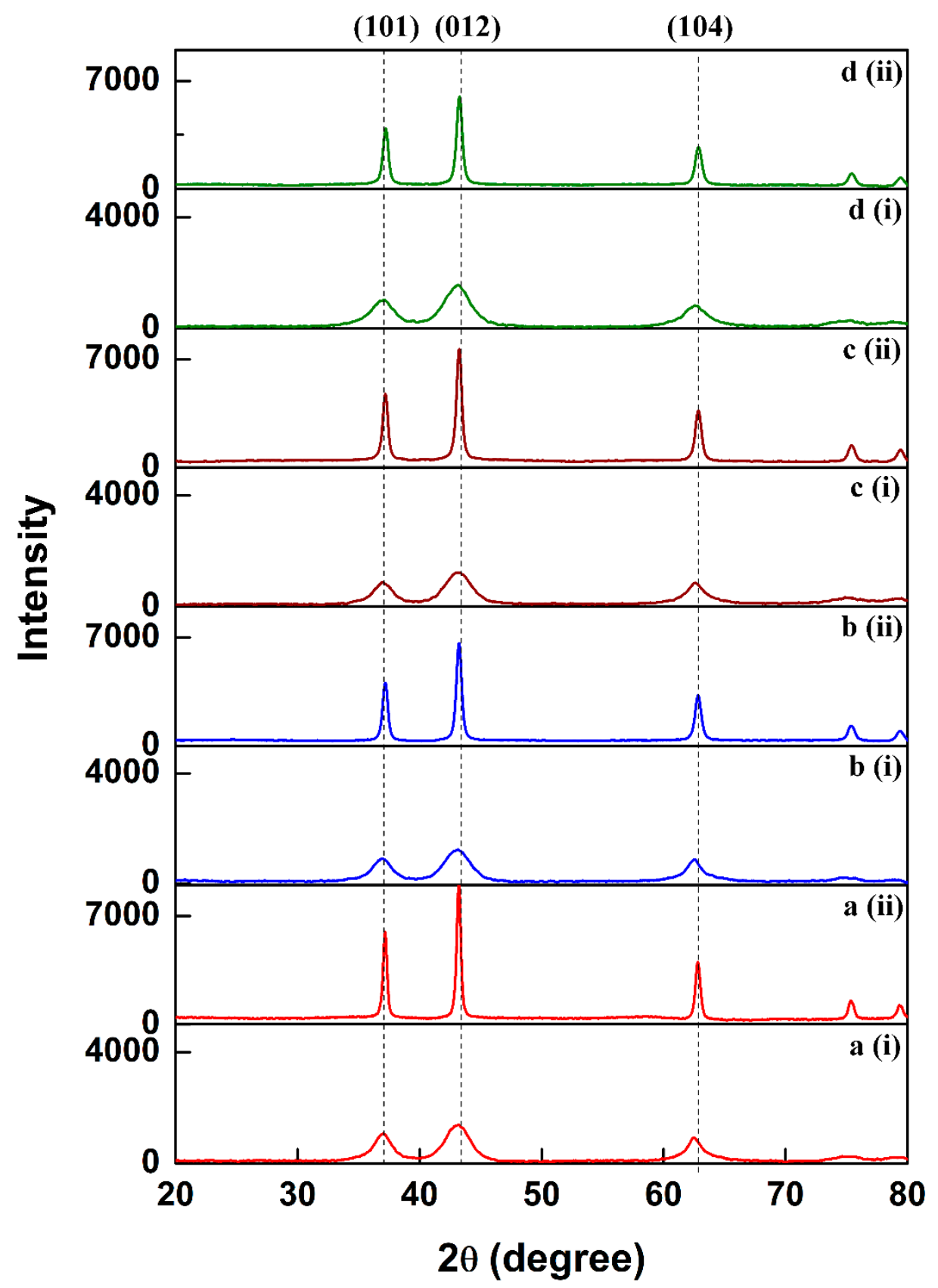

Figure 1. X-ray diffractogram of (a) $\mathrm{NaOH}-$, (b) aloe-vera-, (c) dragon-fruit- and (d) papaya-extractmediated $\mathrm{NiO}_{\mathrm{x}}$ nanoparticles calcined at (i) $300{ }^{\circ} \mathrm{C}$ and (ii) $600{ }^{\circ} \mathrm{C}$.

The average crystal sizes $(D)$ were calculated based on the width of the peak due to the (200) planes by using the Scherrer's formula [13]:

$$
D=\frac{0.94 \lambda}{\beta \operatorname{Cos} \theta}
$$


From Table 1, it could be seen that the average crystallite size of the nanoparticles synthesized with only $\mathrm{NaOH}$ was $15.9 \mathrm{~nm}$, whereas aloe vera, papaya and dragon fruit extracts was $11.5 \mathrm{~nm}, 8.1 \mathrm{~nm}$ and $10.2 \mathrm{~nm}$, respectively. The reduced crystallite size of $\mathrm{NiO}_{x}$ nanoparticles synthesized in presence of plant extracts emphasizes the role of phytochemicals that are able to chelate with metal ions, thus acting as stabilizers or capping agents. Figure 2 illustrates the plausible mechanism for formation of $\mathrm{NiO}_{\mathrm{x}}$ nanoparticles in this study. Upon dissolution, nickel acetate tetrahydrate dissociated to release $\mathrm{Ni}^{2+}$ ions which then combined with hydroxide ions from the base to form $\mathrm{Ni}(\mathrm{OH})_{2}$. The continuous stirring under a heated environment enabled $\mathrm{Ni}(\mathrm{OH})_{2}$ to thermally decompose into $\mathrm{NiO}$ nuclei [14]. The phytochemicals present in each plant extract served as capping ligands which formed interactions with the nanoparticles' surface, leading to steric hindrance and providing eventual stability to the nanocomposite. Hence, the presence of biomass-derived extracts controlled the particle size and minimized agglomeration of the nanoparticles.

Table 1. Particle size calculation based on Debye-Scherrer's equation.

\begin{tabular}{|c|c|c|c|c|c|}
\hline Material & $2 \theta$ & FWHM & $\beta \cos \theta$ & $\begin{array}{l}\text { Crystallite } \\
\text { Size (nm) }\end{array}$ & $\begin{array}{l}\text { Average } \\
\text { Crystallite } \\
\text { Size (nm) }\end{array}$ \\
\hline \multirow{3}{*}{$\mathrm{NiO}-\mathrm{NaOH}$} & 37.4 & 0.51 & 0.0085 & 16.3 & \multirow{3}{*}{15.9} \\
\hline & 43.2 & 0.51 & 0.0083 & 16.8 & \\
\hline & 62.8 & 0.63 & 0.0094 & 14.7 & \\
\hline \multirow{3}{*}{ NiO-Aloe } & 37.4 & 0.71 & 0.0117 & 11.8 & \multirow{3}{*}{11.5} \\
\hline & 43.2 & 0.63 & 0.0101 & 13.6 & \\
\hline & 62.8 & 1.03 & 0.0153 & 9.0 & \\
\hline \multirow{3}{*}{ NiO-Papaya } & 37.4 & 0.90 & 0.0149 & 9.3 & \multirow{3}{*}{10.2} \\
\hline & 43.2 & 0.68 & 0.0109 & 12.6 & \\
\hline & 62.8 & 1.08 & 0.0160 & 8.6 & \\
\hline \multirow{3}{*}{ NiO-Dragon } & 37.4 & 1.62 & 0.0269 & 5.2 & \multirow{3}{*}{8.1} \\
\hline & 43.2 & 0.68 & 0.0109 & 12.6 & \\
\hline & 62.8 & 1.45 & 0.0216 & 6.4 & \\
\hline
\end{tabular}

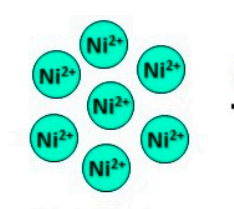

Nickel (II) ions

reaction with base

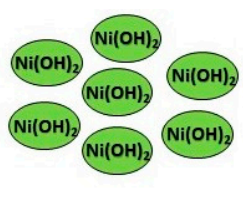

Nickel (II) hydroxide

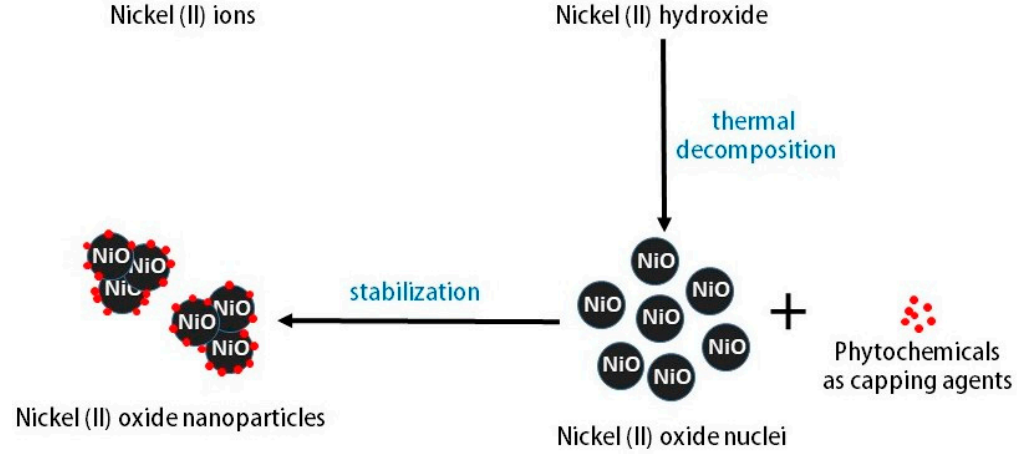

Figure 2. Plausible mechanism for green synthesis of $\mathrm{NiOx}$ nanoparticles.

\subsection{Morphological Properties}

The morphological properties of the synthesized $\mathrm{NiO}_{x}$ nanoparticles are shown in Figure 3. From the images, it is clear that the $\mathrm{NiO}_{\mathrm{x}}$ nanoparticles were sphericalshaped, densely packed and intercalated with each other. Dragon fruit and papaya-extractmediated $\mathrm{NiO}_{x} \mathrm{NPs}$ depict well-defined nanostructures with fewer intercalations. The particle size distribution for the $\mathrm{NiO}_{x} \mathrm{NPs}$ synthesized without extract ranged between 


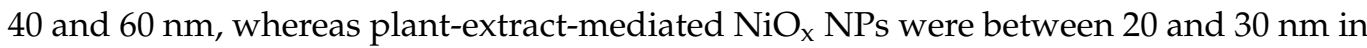
size. The trend in particle size coincided with the trend in crystallite size derived from the XRD analysis. For all the samples, the particle size revealed in morphological analysis was higher than average crystallite size estimated from XRD analysis, hence indicating that the single $\mathrm{NiO}_{x}$ particle is made up of few crystallites.
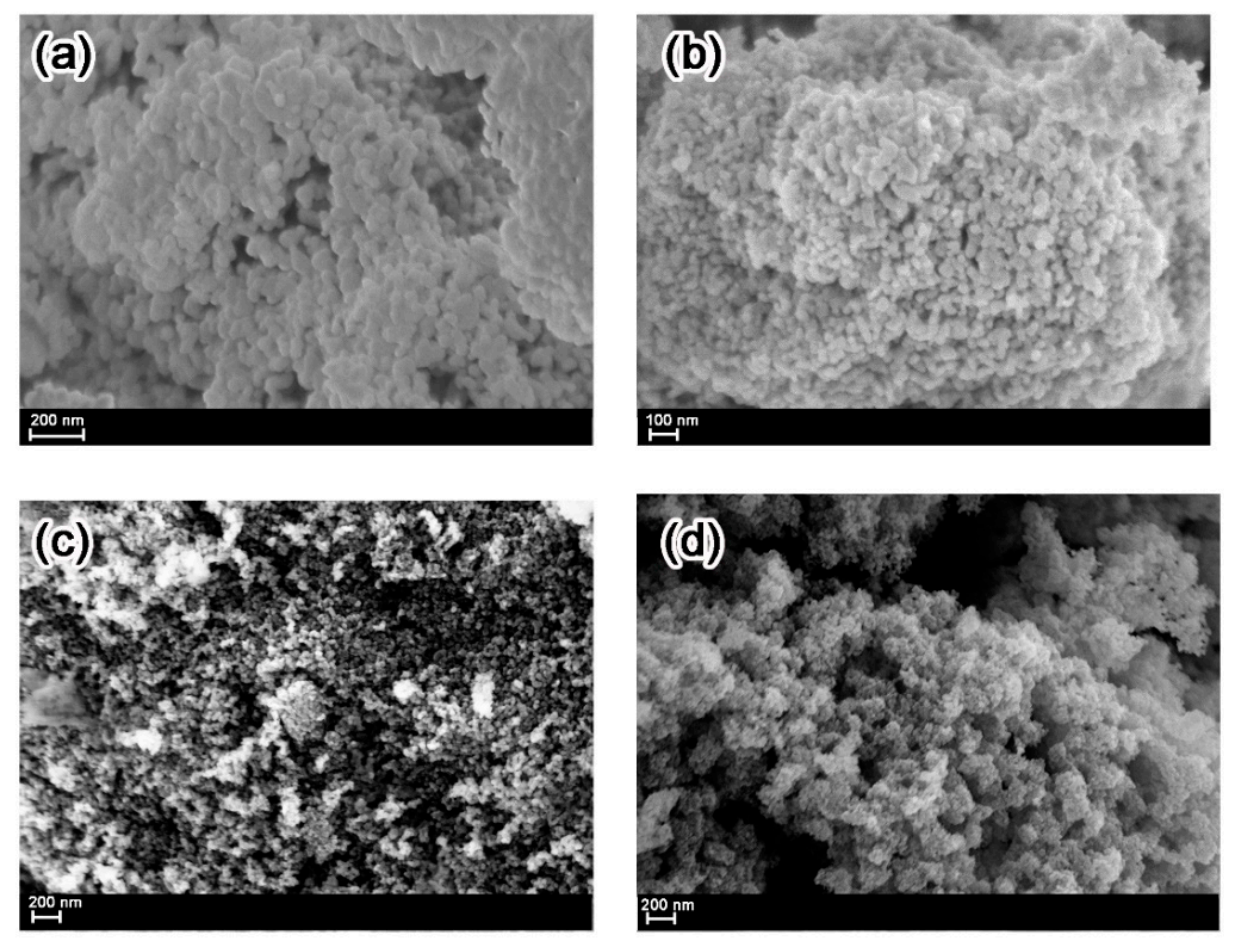

Figure 3. FESEM images of (a) NaOH-, (b) aloe-vera-, (c) dragon-fruit- and (d) papaya-extractmediated $\mathrm{NiO}_{\mathrm{x}}$ nanoparticles.

The elemental composition of the nanoparticles was verified from EDX analysis. As shown in Figure 4, the choice of plant extract influenced the composition of nickel and oxygen in the samples. $\mathrm{NiO}_{\mathbf{x}} \mathrm{NPs}$ synthesized using aloe vera were more oxygen deficient compared to papaya and dragon fruit. Aloe-vera-mediated nickel oxide also exhibited the highest amount of residual carbon, despite calcining the samples at $600{ }^{\circ} \mathrm{C}$. It is deduced that this could be due to the more viscous nature of the aloe vera extract, which adheres to the surface of the nanoparticles during synthesis. The absence of residual carbon originating from the phytochemicals was evident in dragon-fruit- and papaya-extract-mediated $\mathrm{NiO}_{\mathrm{x}}$ NPs, which could explain the occurrence of fewer intercalations, as shown in the FESEM images.

\subsection{Optical Properties}

The absorption spectrum of the $\mathrm{NiO}_{\mathrm{x}}$ nanoparticles, as shown in Figure 5a, was recorded at room temperature within the range of $200-800 \mathrm{~nm}$. There was a peak observed at around 300-350 $\mathrm{nm}$ for all synthesized nanopowders, which can be assigned to the exciton transitions [15]. The band gap energies were estimated by extrapolation using Tauc plots, and the energy curves are shown in Figure 5. It was seen that the band gap of $\mathrm{NiO}_{x}$ nanoparticle synthesis in different samples were ranging from 3.09 to $3.22 \mathrm{eV}$ and the band gap was slightly increased for plant-extract-assisted synthesized nanoparticles. Particularly, the decrease in particle size, as well as the increase in band gap energy of the as-prepared nanoparticles, signified the size quantization effects [16]. When particle size reached the nanosized scale, the overlapping of adjacent energy levels minimized and, subsequently, the width of energy band widened $[17,18]$. 

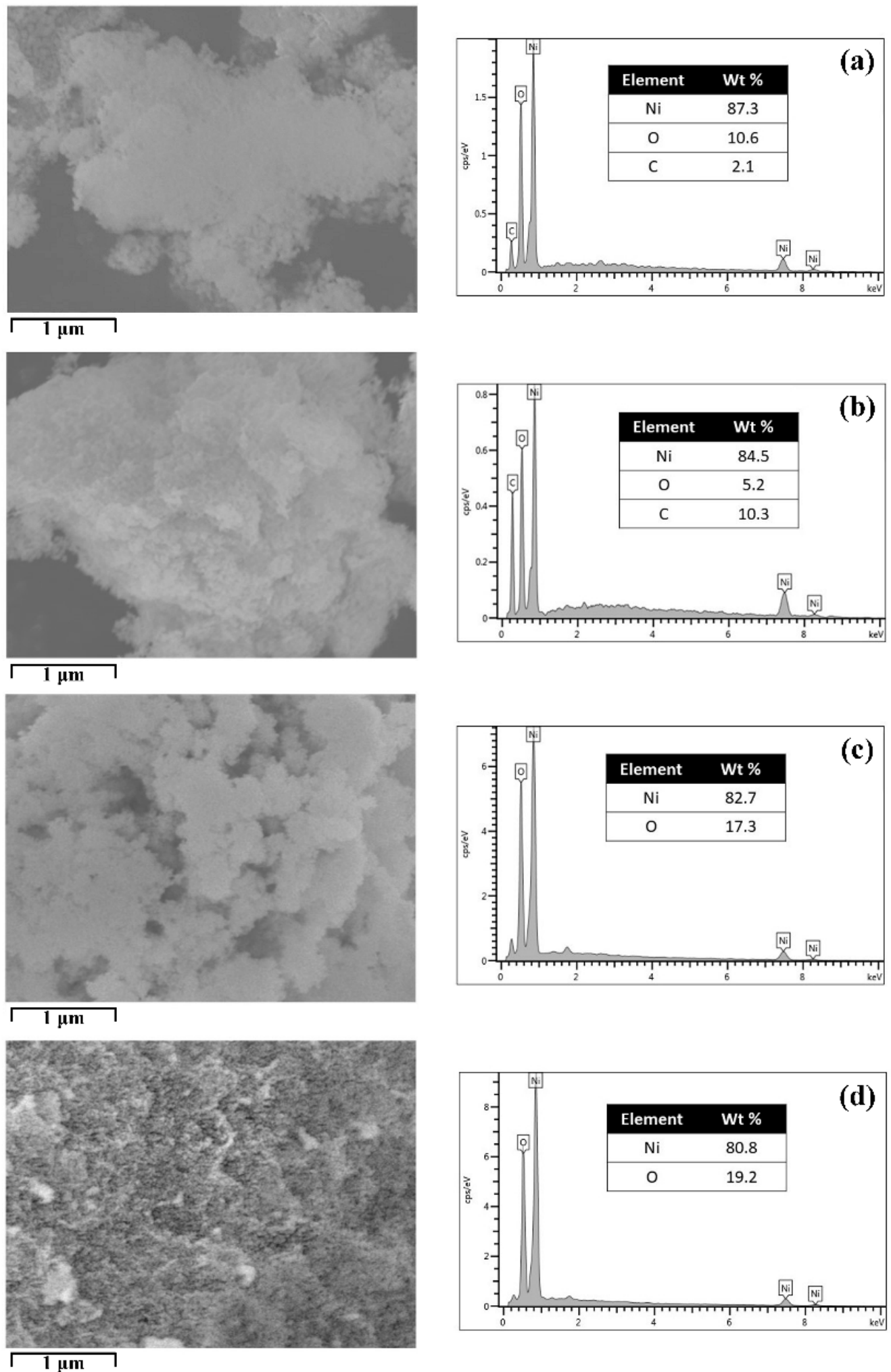

Figure 4. EDX spectrum of (a) $\mathrm{NaOH}_{-}$, (b) aloe-vera-, (c) dragon-fruit- and (d) papaya-extractmediated $\mathrm{NiO}_{\mathrm{x}}$ nanoparticles. 

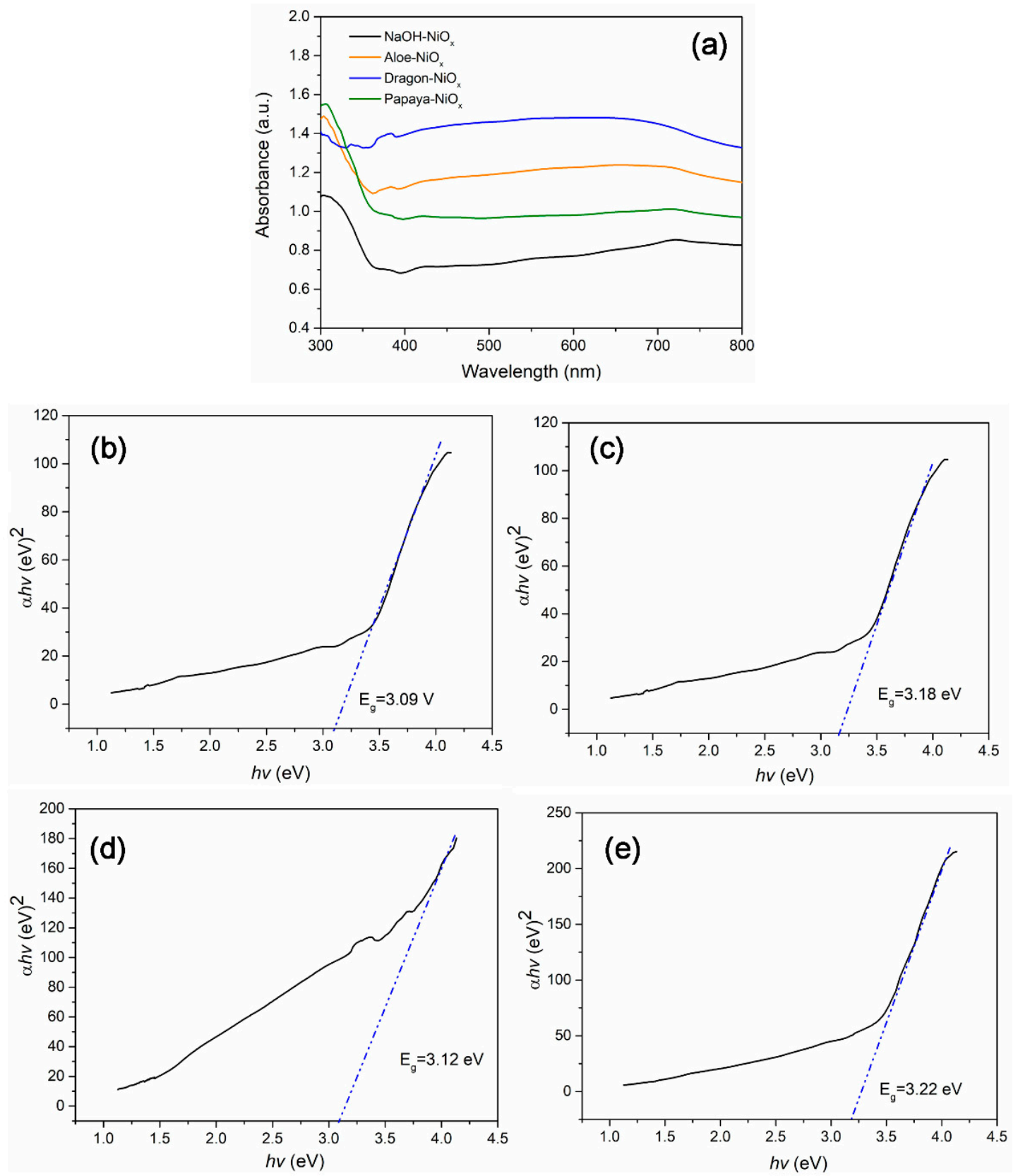

Figure 5. (a) UV-Vis absorption spectrum and the corresponding Tauc plot of (b) NaOH-, (c) aloe-vera-, (d) dragon-fruitand (e) papaya-extract-mediated $\mathrm{NiO}_{\mathrm{x}}$ nanoparticles.

\subsection{Electrocatalytic Properties for Oxygen Evolution Reaction (OER)}

The electrocatalytic activity of the synthesized $\mathrm{NiO}_{x}$ NPs towards OER was explored by performing linear scanning voltammetry (LSV) in an aqueous solution of $1.0 \mathrm{M} \mathrm{KOH}$. Generally, the oxygen evolution reaction in alkaline medium is represented as follows [19-21]:

$$
4 \mathrm{OH}^{-} \rightarrow \mathrm{O}_{2}+2 \mathrm{H}_{2} \mathrm{O}+4 e^{-}
$$

The four-electron reaction mechanism can be described sequentially via the following equations:

$$
\begin{aligned}
\mathrm{OH}^{-} & \rightarrow \mathrm{OH}^{*}+e^{-} \\
\mathrm{OH}^{*}+\mathrm{OH}^{-} & \rightarrow \mathrm{O}^{*}+\mathrm{H}_{2} \mathrm{O}+e^{-} \\
\mathrm{O}^{*}+\mathrm{OH}^{-} & \rightarrow \mathrm{OOH}^{*}+e^{-}
\end{aligned}
$$




$$
\mathrm{OOH}^{*}+\mathrm{OH}^{-} \rightarrow \mathrm{O}_{2}+2 \mathrm{H}_{2} \mathrm{O}+e^{-}
$$

where $\mathrm{OH}^{*}, \mathrm{O}^{*}$ and $\mathrm{OOH}^{*}$ indicate the species adsorbed to the active site of the catalyst.

Based on the polarization curves shown in Figure 6a, to attain the current density of $10 \mathrm{~mA} \mathrm{~cm}^{-2}$, aloe-vera- and papaya-extract-mediated $\mathrm{NiO}_{\mathrm{x}} \mathrm{NPs}$ exhibited the overpotential values of $416 \mathrm{mV}$ and $433 \mathrm{mV}$, respectively, which are lower than $\mathrm{NaOH}$-based $\mathrm{NiO}_{x}$, which records $474 \mathrm{mV}$. Interestingly, dragon-fruit-extract-mediated $\mathrm{NiO}_{x}$ showed the overpotential of $501 \mathrm{mV}$, the highest overpotential compared to the previous three samples. As listed in Table 2, the onset potential, which indicates the voltage at which current begins to rise, was lowest for aloe-vera-mediated NPs and highest for dragon fruit.
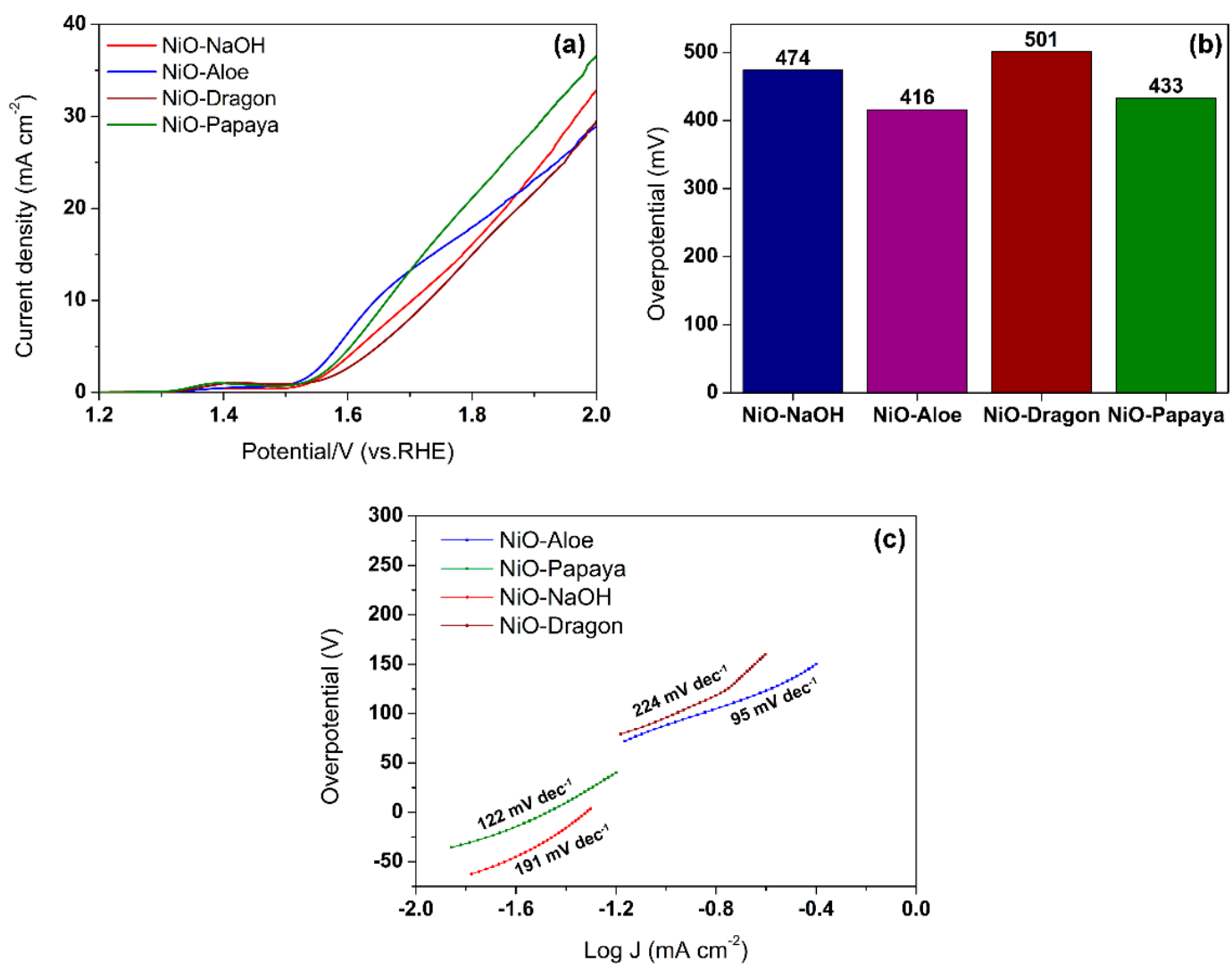

Figure 6. (a) Polarization curve by linear sweep voltammetry, (b) overpotential at $10 \mathrm{~mA} \mathrm{~cm}^{-2}$ and (c) Tafel plot.

Table 2. Electrocatalytic parameters of $\mathrm{NiO}_{x}$ nanoparticles.

\begin{tabular}{|c|c|c|c|}
\hline Material & $\begin{array}{l}\text { Onset Potential } \\
\text { (V) }\end{array}$ & $\begin{array}{c}\text { Overpotential } \\
\text { at } 10 \mathrm{~mA} \mathrm{~cm}^{-2}(\mathrm{mV})\end{array}$ & $\begin{array}{l}\text { Tafel Slope } \\
(\mathrm{mV} \mathrm{dec}-1)\end{array}$ \\
\hline $\mathrm{NiO}-\mathrm{NaOH}$ & 1.57 & 474 & 191 \\
\hline NiO-Aloe & 1.54 & 416 & 95 \\
\hline NiO-Papaya & 1.56 & 433 & 122 \\
\hline NiO-Dragon & 1.59 & 501 & 224 \\
\hline
\end{tabular}

The plausible reaction mechanism of $\mathrm{NiO}_{\mathbf{x}}$ for OER is outlined as follows:

$$
\begin{aligned}
\mathrm{Ni}^{2+}+3 \mathrm{OH}^{-} & \leftrightarrow \mathrm{NiOOH}+\mathrm{H}_{2} \mathrm{O}+e^{-} \\
\mathrm{NiOOH}+\mathrm{OH}^{-} & \leftrightarrow \mathrm{NiO}(\mathrm{OH})_{2}+e^{-} \\
\mathrm{NiO}(\mathrm{OH})_{2}+2 \mathrm{OH}^{-} & \leftrightarrow \mathrm{NiOO}_{2}+2 \mathrm{H}_{2} \mathrm{O}+2 e^{-} \\
\mathrm{NiOO}_{2}+2 \mathrm{OH}^{-} & \leftrightarrow \mathrm{NiOOH}+\mathrm{O}_{2}+e^{-}
\end{aligned}
$$


Throughout the electrocatalytic process, $\mathrm{Ni}^{2+}$ ions that can be present on surface of the $\mathrm{NiO}_{x} \mathrm{NPs}$ will undergo oxidation to form $\mathrm{Ni}^{3+}$ ions which then aid to catalyze the oxidation of $\mathrm{OH}^{-}$ions, leading to the formation of water [22].

To further comprehend the reaction kinetics of the nickel-oxide-based electrocatalysts, the Tafel plot was plotted (Figure 6c), and the linear section of Tafel slope was derived from the following equation:

$$
\eta=b \log j+a
$$

where $\eta$ is the overpotential, $b$ is the Tafel slope and $\mathrm{j}$ refers to current density. $\mathrm{NaOH}$-, aloe-vera-, papaya- and dragon-fruit-mediated $\mathrm{NiO}_{\mathrm{x}}$ recorded slope values of 191, 95, 122 and $224 \mathrm{mV} /$ decade, respectively. The Tafel slope values indicate the rate-limiting step which is attributed to the reaction with first electron transfer. Thus, the lower Tafel slope value of aloe-vera-mediated $\mathrm{NiO}_{\mathrm{x}} \mathrm{NPs}$ translates to more efficient reaction kinetics for OER. One of the proposed explanations for the superior electrocatalytic performance of aloe-vera-mediated $\mathrm{NiO}_{x} \mathrm{NPs}$ can be related to the relatively high oxygen deficiency in the samples, as evidenced by EDX measurements. The non-stoichiometric composition most likely led to the presence of surface defects, which have been found to enhance the electrocatalytic performance of metal oxides for OER [23,24].

Another key factor that governs the performance of electrocatalyst is the surface area available as active sites for catalytic activities. In OER, electrochemically active surface area (ECSA) is used as the parameter to assess the specific catalytic activity of an electrocatalyst, and it can be derived from electrochemical double-layer capacitance $\left(C_{d l}\right)$. To calculate $C_{d l}$ values, the samples were subjected to cyclic voltammetry $(C V)$ at different scan rates in the non-Faradaic segment where the voltage was scanned from 1.46 to $1.56 \mathrm{~V}$ vs. RHE (Figure 7). The double-layer capacitance was then derived based on the gradient of linear plot of $\Delta \mathrm{J}=\left(\mathrm{J}_{\mathrm{a}}-\mathrm{J}_{\mathrm{c}}\right.$ ) (where $\mathrm{J}_{\mathrm{a}}$ and $\mathrm{J}_{\mathrm{c}}$ are anodic and cathodic current density) at $1.52 \mathrm{~V}$ vs. RHE as a function of the scan rate [25]. The ECSA was then calculated from the double-layer capacitance based on the following equation:

$$
E C S A=\frac{C_{d l}}{C_{S}}
$$

where $C_{s}$ is the specific capacitance which is equated to $0.040 \mathrm{mF} \mathrm{cm}^{-2}$ based on the conventional value for metal electrode in $\mathrm{KOH}$ solution. The roughness factor $\left(\mathrm{R}_{\mathrm{f}}\right)$ can then be evaluated by dividing ECSA by the electrode area. Table 3 summarizes the ECSA and roughness factor for all the samples. Papaya-mediated $\mathrm{NiO}_{x} \mathrm{NPs}$ exhibit the highest value of ECSA and $R_{f}$ of $5.50 \mathrm{mFcm}^{-2}$ and 1936, respectively, thus indicating that it has the highest catalytically active surface area. This could be the boosting factor that supports the low overpotential value recorded by papaya-mediated $\mathrm{NiO}_{x} \mathrm{NPs}$ despite its high Tafel slope. The variation of active surface area of the electrocatalysts prepared using different plant extracts further emphasizes the role of phytochemicals in fine-tuning the morphology and size distribution of nanoparticles during the synthesis process.

Table 3. Electrochemical active surface area and double-layer capacitance of $\mathrm{NiO}_{\mathrm{x}}$ nanoparticles.

\begin{tabular}{cccc}
\hline Material & $\mathbf{C}_{\boldsymbol{d l}}\left(\mathbf{m F ~} \mathbf{~ m}^{-\mathbf{2}}\right)$ & ECSA $\left.\mathbf{( c m}^{\mathbf{2}}\right)$ & $\mathbf{R}_{\mathbf{f}}$ \\
\hline $\mathrm{NiO}-\mathrm{NaOH}$ & 4.50 & 112.50 & 1584 \\
$\mathrm{NiO}-$ Aloe & 4.80 & 120.00 & 1690 \\
$\mathrm{NiO}-$ Papaya & 5.50 & 137.50 & 1936 \\
$\mathrm{NiO}-$ Dragon & 2.25 & 56.25 & 792 \\
\hline
\end{tabular}



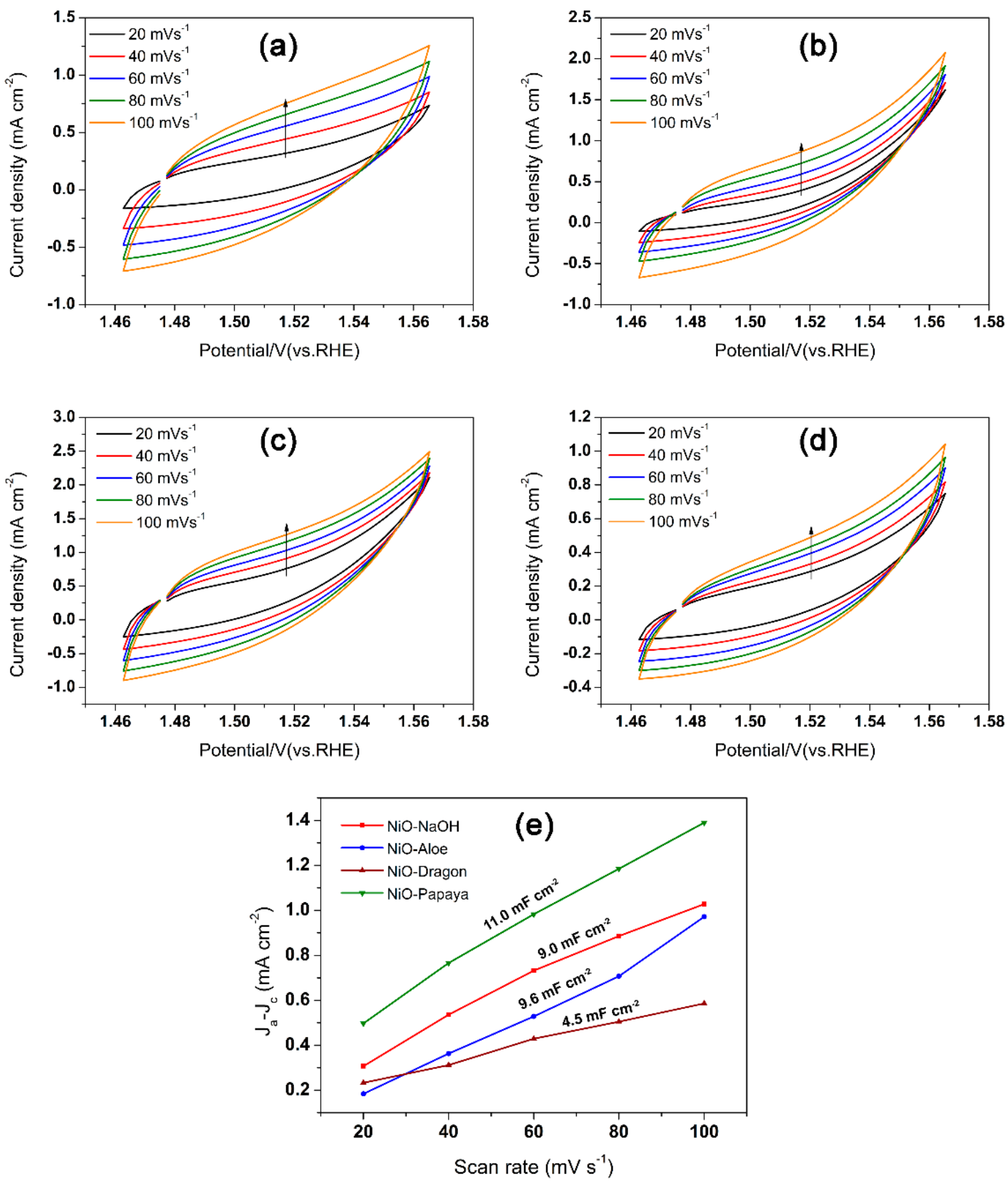

Figure 7. Cyclic voltammogram of (a) $\mathrm{NaOH}_{-}$, (b) aloe-vera-, (c) dragon-fruit- and (d) papaya-extract-mediated $\mathrm{NiO}_{x}$ nanoparticles and (e) linear plot between current density and scan rate.

Electrochemical impedance spectroscopy (EIS) is a powerful technique that allows us to obtain insights on electrode-electrolyte interface dynamics. The EIS measurements for all the samples were performed with a frequency range from $0.1 \mathrm{~Hz}$ to $100 \mathrm{kHz}$, and the resulting Nyquist plots comprising of semicircles are presented in Figure 8. The starting point of the semicircle signifies the internal resistance (also known as solution resistance $\left(R_{S}\right)$ ) of the catalyst, whereas the diameter of the semicircle denotes chargetransfer resistance between the electrode-electrolyte interfaces $\left(R_{C T}\right)$ [26]. In terms of equivalent circuit, the depressed semicircle is represented by $R_{S}$ connected in series to the 
capacitor $\left(\mathrm{Q}_{\mathrm{DL}}\right)$ and $\mathrm{R}_{\mathrm{CT}}$ in a parallel arrangement, as shown in Figure 8. The following equation evaluates impedance values according to the described equivalent circuit [27]:

$$
Z_{D S S C}=R_{S}+\frac{R_{C T}}{1+(j \omega)^{n_{C T}} R_{C T} Q_{C T}}
$$

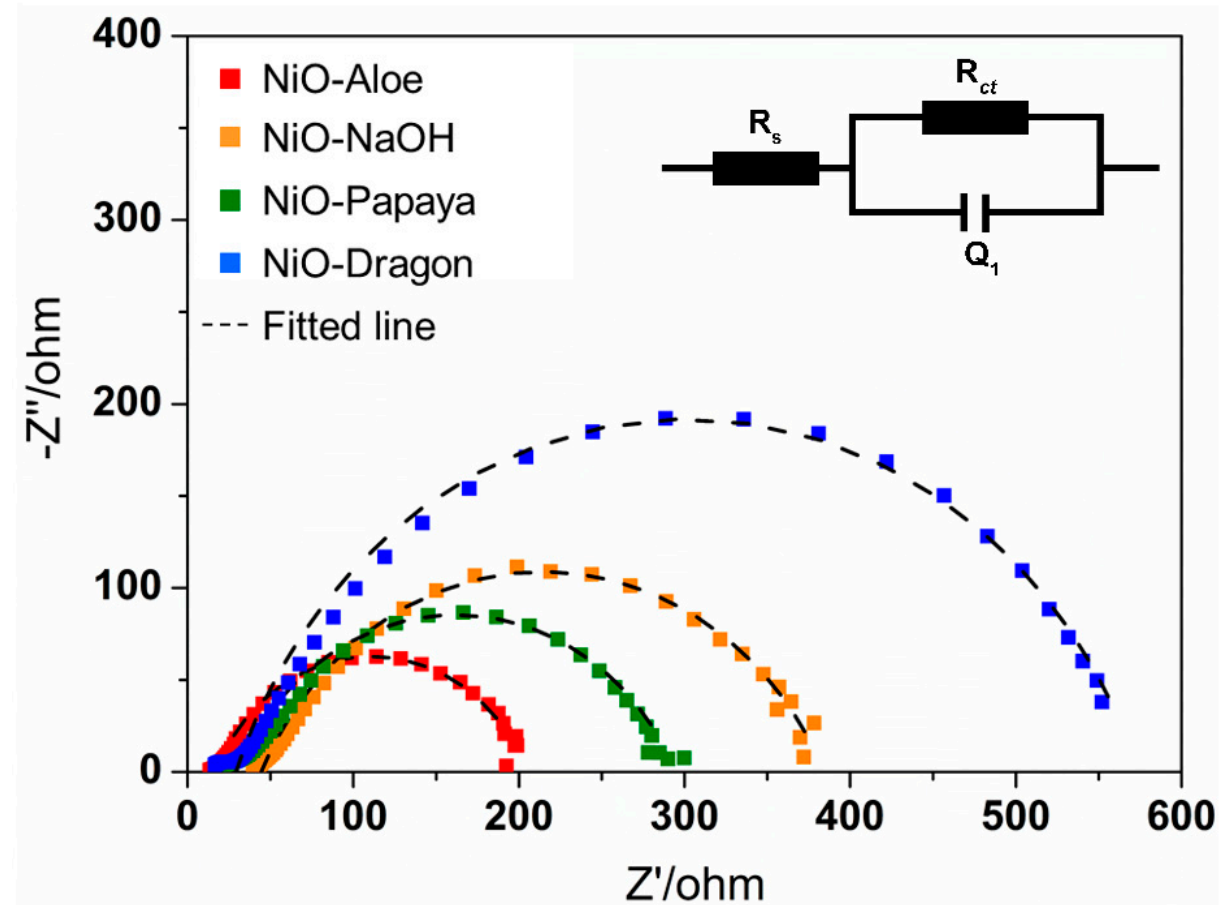

Figure 8. Nyquist plots from EIS analysis.

The equation was used to fit the Nyquist plots and the solution resistance, chargetransfer resistance and double-layer capacitance based on the equivalent circuit fitting are tabulated in Table 4. Typically, charge-transfer resistance $\left(\mathrm{R}_{\mathrm{CT}}\right)$ is considered the most significant parameter as it dictates the extent of electronic transfers between the reactant and electrocatalyst surface. A lower $\mathrm{R}_{\mathrm{CT}}$ value also indicates higher conductivity of the electrocatalyst material which favors electron mobility during the electrocatalytic reaction [28]. In this study, aloe-vera-mediated $\mathrm{NiO}_{x} \mathrm{NPs}$ showed the lowest solution resistance and charge-transfer resistance. This can be attributed to better conductivity of the $\mathrm{NiO}_{\mathrm{x}} \mathrm{NPs}$ due to its higher oxygen deficiency compared to other green-synthesized nanoparticles. Therefore, it is evident that efficient charge-transfer kinetics and improved conductivity is one of the crucial factors for the higher electrocatalytic performance of aloe-vera-mediated $\mathrm{NiO}_{x} \mathrm{NPs}$ compared to its dragon fruit and papaya counterparts.

Table 4. Equivalent circuit fitting parameters for the EIS analysis.

\begin{tabular}{cccc}
\hline Material & $\mathbf{R}_{\mathbf{S}}(\boldsymbol{\Omega})$ & $\mathbf{R}_{\mathbf{C T}}(\boldsymbol{\Omega})$ & $\mathbf{Q}_{\text {DL }}(\mathbf{F})$ \\
\hline NiO-NaOH & 44.5 & 339.9 & $3.04 \times 10^{-4}$ \\
NiO-Aloe & 17.0 & 187.9 & $3.59 \times 10^{-4}$ \\
NiO-Papaya & 29.2 & 265.6 & $2.72 \times 10^{-4}$ \\
NiO-Dragon & 29.4 & 544.5 & $1.54 \times 10^{-4}$ \\
\hline
\end{tabular}

To evaluate the stability of aloe-vera-mediated $\mathrm{NiO}_{x} \mathrm{NPs}$, chronoamperometry analysis was performed for $24 \mathrm{~h}$ at an overpotential of $415 \mathrm{mV}$. Within the first $2 \mathrm{~h}$, it was observed that there was a gradual increase in current density. This is attributed to the activation of nickel oxide into nickel oxyhydroxide $(\mathrm{NiOOH})$ during the initial part of 
the analysis [22]. Higher conductivity of $\mathrm{NiOOH}$ compared to $\mathrm{NiO}$ rendered the gradual increase in current density. As the chronoamperometry was extended for $24 \mathrm{~h}$, the current density remained stable without any significant decay.

The stability of the final product was further verified by subjecting the $\mathrm{NiO}_{\mathrm{x}}$-modified glassy carbon electrode to cyclic voltammetry (CV) analysis for 500 continuous cycles, which were carried out between 1.2 and $1.8 \mathrm{~V}$ at a scan rate of $100 \mathrm{mVs}^{-1}$. As shown in Figure 9, after $500 \mathrm{CV}$ cycles, the overpotential of aloe-vera-mediated $\mathrm{NiO}_{\mathrm{x}} \mathrm{NPs}$ increased from $416 \mathrm{mV}$ to $428 \mathrm{mV}$ with a difference of only $0.12 \mathrm{mV}$ at the current density of $10 \mathrm{~mA} \mathrm{~cm}^{-2}$. This observation validates the high electrocatalytic stability of the greensynthesized nickel oxide nanoparticle for OER activity.

(a)

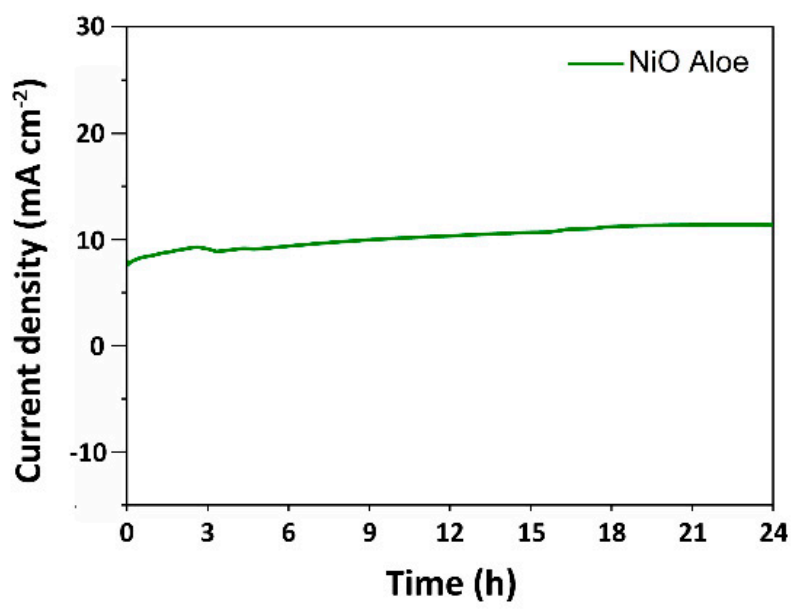

(b)

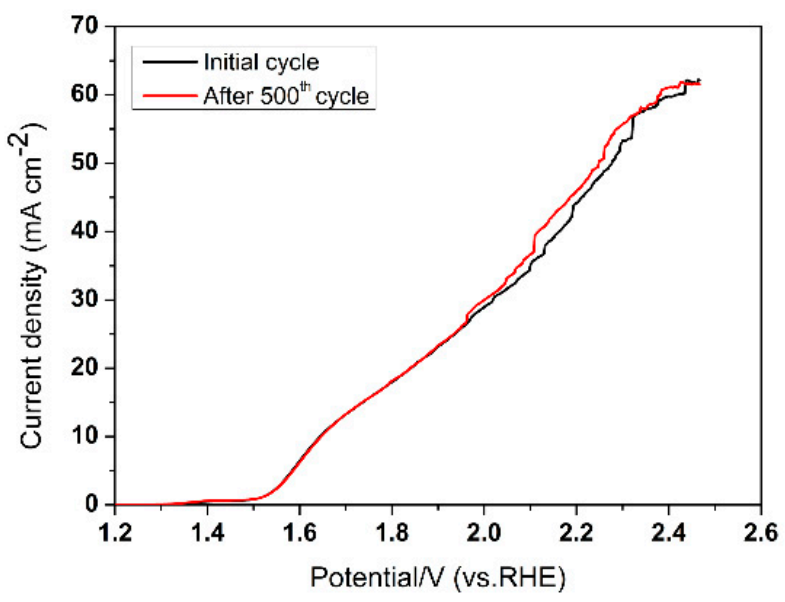

Figure 9. (a) Chronoamperometric stability tests at $1.65 \mathrm{~V}$ (vs the RHE) and (b) LSV curves obtained before and after $500 \mathrm{CV}$ cycles of aloe-vera-mediated $\mathrm{NiOx}$ NPs.

\section{Materials and Methods}

\subsection{Chemicals}

Nickel acetate tetrahydrate $\left(\mathrm{Ni}\left(\mathrm{CH}_{3} \mathrm{COO}\right)_{2} \cdot 4 \mathrm{H}_{2} \mathrm{O}\right), \mathrm{NaOH}$ and $\mathrm{KOH}$ were purchased from Sigma Aldrich, Hamburg, Germany. Deionized (DI) water was used to prepare all types of solution. All the other chemicals were of analytical reagent grade and used without any further purification.

\subsection{Preparation of Plant Extract}

The $\mathrm{NiO}_{\mathrm{x}}$ nanoparticles were synthesized using various plant extracts such as aloe vera leaf extract, dragon fruit peel extract and papaya peel extract. $\mathrm{NiO}_{x} \mathrm{NPs}$ without extract were also synthesized. Different plant samples were collected from the local market at Hentian Kajang, Selangor, Malaysia. In order to prepare the plant extract, at first, $50 \mathrm{~g}$ of different plant samples were washed with DI water, cut into small pieces and were taken in three different $500 \mathrm{~mL}$ glass beakers and $250 \mathrm{~mL}$ DI water was added to all the beakers. Then the mixtures were heated at $60-70{ }^{\circ} \mathrm{C}$ for $30 \mathrm{~min}$ with continuous stirring. After heating, the extracts were filtered with vacuum filter and the filtrates were collected in three different $500 \mathrm{~mL}$ reagent bottles.

\subsection{Synthesis of $\mathrm{NiO}_{x}$ Nanoparticle}

The $\mathrm{NiO}_{\mathrm{x}}$ nanoparticles were synthesized using the green synthesis technique. In this technique, at first, $30 \mathrm{~mL}(1 \mathrm{M})$ nickel acetate solutions were heated in four different $250 \mathrm{~mL}$ glass beakers at $60-70{ }^{\circ} \mathrm{C}$ temperature with continuous stirring. Then, $30 \mathrm{~mL}$ DI water was added to the first beaker (without extract) and $30 \mathrm{~mL}$ of three different plant extracts to the other three beakers was added in the precursor solution with constant heating 
(60-70 ${ }^{\circ} \mathrm{C}$ temperature) and stirring. Then, $1 \mathrm{M} \mathrm{NaOH}$ solution was added, dropwise, into the reaction mixture with vigorous stirring and heating for $2 \mathrm{~h}$. After completion of the reaction, the mixtures were washed with DI water several times and filtered using Whatman 1 filter paper. Finally, the synthesized NPs were dried in an oven at $100{ }^{\circ} \mathrm{C}$ overnight, calcined at $300{ }^{\circ} \mathrm{C}$ and $600{ }^{\circ} \mathrm{C}$ for $6 \mathrm{~h}$, powdered using mortar-pastel and stored in the glass vial for further analysis. Figure 10 represents the schematic view of green synthesis process of $\mathrm{NiO}_{x} \mathrm{NPs}$.

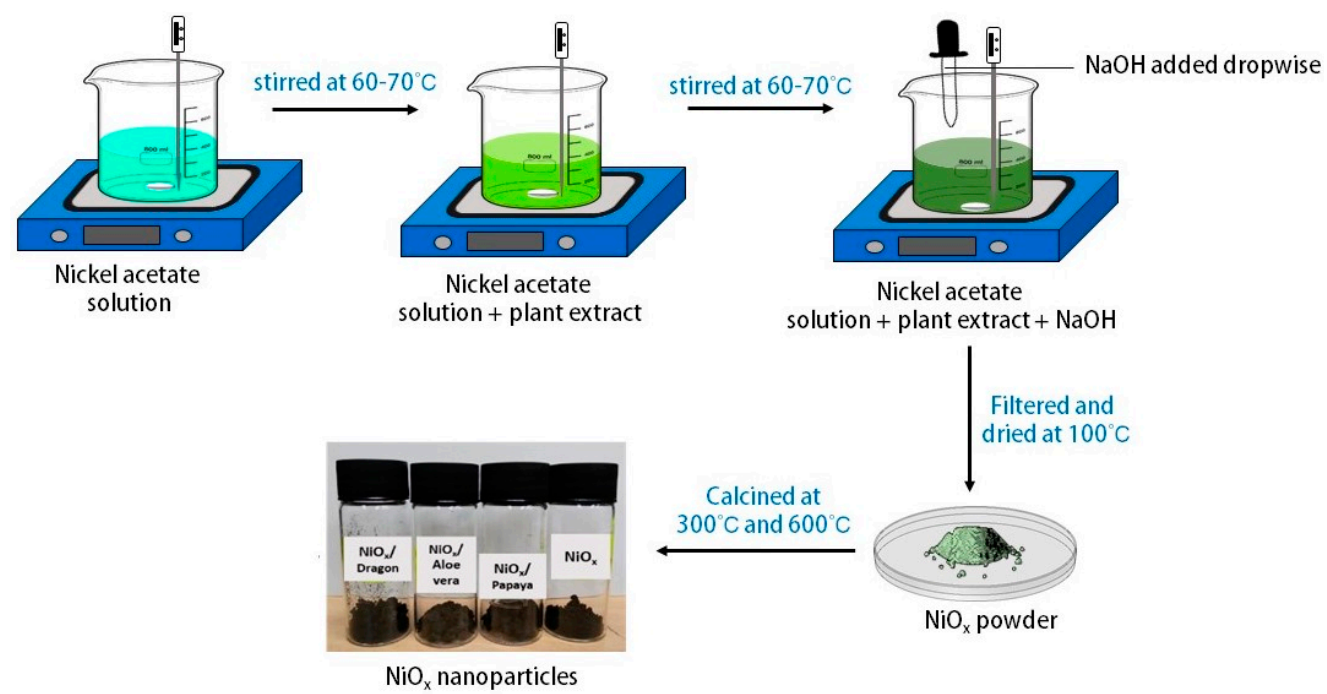

Figure 10. Reaction scheme for green synthesis process of NiOx NPs.

\subsection{Characterization of Materials}

The morphological and structural properties of synthesized $\mathrm{NiO}_{x}$ nanoparticles were examined using various characterization techniques such as X-ray diffraction (XRD), absorption spectra (UV-Vis) and field-emission scanning electron microscopy (FESEM), along with energy dispersive $X$-ray (EDX). The XRD patterns were taken in the $2 \theta$ ranging from $10^{\circ}$ to $80^{\circ}$ using BRUKER aXS-D8 Advance Cu-Ka diffractometer (Bruker, MA, USA). The FESEM model LEO $1450 \mathrm{Vp}$ was used for investigating the surface morphology, as well as grain size and growth of the $\mathrm{NiO}_{\mathrm{x}}$ nanoparticles. The optoelectronic properties of the synthesized nanocatalyst, such as the optical transmittance, absorbance and optical band gap, were calculated using UV-Vis spectrometer Perkin Elmer Instruments Lambda35 (PerkinElmer, Waltham, MA, USA).

\subsection{Electrochemical Characterization}

Electrochemical characterization was performed using Metrohm Autolab workstation (Metrohm, Herisau, Switzerland) in a three-electrode setup in which platinum electrode and silver/silver chloride were used as the counter electrode and reference electrode, respectively. The $\mathrm{NiO}_{x} \mathrm{NPs}$ were drop casted onto glassy carbon electrode with an active area of $0.07 \mathrm{~cm}^{2}$ to function as the working electrode. A $5 \mathrm{mg}$ amount of the $\mathrm{NiO}_{\mathrm{x}} \mathrm{NPs}$ was mixed with $250 \mu \mathrm{L}$ ethanol, $250 \mu \mathrm{L}$ deionized water and $50 \mu \mathrm{L}$ of Nafion ( $5 \mathrm{wt} \%$ ). The dispersion was sonicated for an hour and $10 \mu \mathrm{L}$ of the dispersion was drop casted on top of the glassy carbon electrode surface followed by drying. Linear sweep voltammetry between 0 and $1 \mathrm{~V}$ with scan rate of $5 \mathrm{mV} \mathrm{s}^{-1}$ was performed to evaluate the oxygen evolution reaction. The measured potential vs. $\mathrm{Ag} / \mathrm{AgCl}$ was converted to a reversible hydrogen electrode (RHE) based on the following equation:

$$
E_{R H E}=E_{A g / A g C l}+0.059 p H+E_{A g / A g C l}^{0}
$$


where $E_{A g / A g C l}^{0}$ is $0.1976 \mathrm{~V}$ at $25^{\circ} \mathrm{C}$ and $E_{A g / A g C l}$ is measured potential vs. $\mathrm{Ag} / \mathrm{AgCl}$. The overpotential is calculated by measuring the difference between measured potential vs. RHE at current density of $10 \mathrm{~mA} \mathrm{~cm}^{-2}$ and the standard value of $1.23 \mathrm{~V}$.

\section{Conclusions}

Utilization of different plant extracts as capping agents affects the structural and morphological properties of $\mathrm{NiO}_{x}$ NPs. FESEM results show that $\mathrm{NiO}_{x} \mathrm{NPs}$ synthesized without extract had a particle size between 40 and $60 \mathrm{~nm}$, whereas plant-extract-mediated $\mathrm{NiO}_{x}$ were between 20 and $30 \mathrm{~nm}$. The reduction in particle size upon introducing plant extracts was further supported by the shifting of the band gap to a higher value based on optical characterization. EDX analysis reveal that aloe vera, papaya and dragon fruit extract yielded $\mathrm{NiO}_{x} \mathrm{NPs}$ with different oxygen and nitrogen stoichiometry. The deficiency of oxygen is higher in aloe vera-mediated $\mathrm{NiO}_{x} \mathrm{NPs}$, which might elevate its conductivity and thus lead to lower charge-transfer resistance in EIS analysis. ECSA calculation based on cyclic voltammetry indicated that the highest electrocatalytic surface area was possessed by papaya-extract-mediated $\mathrm{NiO}_{\mathrm{x}} \mathrm{NPs}$, followed by aloe vera and dragon fruit extract. Overall, the best electrocatalytic performance is attributed to aloe vera-extract-mediated $\mathrm{NiO}_{x} \mathrm{NPs}$, which only required $433 \mathrm{mV}$ overpotential to reach $10 \mathrm{mAcm}^{-2}$ with a Tafel slope of $95 \mathrm{mVdec}^{-1}$.

Author Contributions: Conceptualization, V.S, M.S. and S.S.; methodology, M.S., D.K.S. and M.A. (Mohammod Aminuzzaman); formal analysis, F.H.A. and Z.Z.; writing — original draft preparation, V.S. and S.S.; writing—review and editing, H.I.A. and N.A.; supervision, M.A. (Md. Akhtaruzzaman); project administration, H.A. and M.A. (Md. Akhtaruzzaman); funding acquisition, H.I.A. and N.A. All authors have read and agreed to the published version of the manuscript.

Funding: The authors are highly grateful to Universiti Kebangsaan Malaysia for supporting this study through the Modal Insan fellowship (RFA1). Authors also extend their appreciation to The University Researchers Supporting Project Number (TURSP-2020/264), Taif University, Taif, Saudi Arabia. Authors are thankful to Universiti Tunku Abdul Rahman (UTAR) providing necessary research facilities to carry out this research work successfully.

Data Availability Statement: Not applicable.

Acknowledgments: The authors are highly grateful to Universiti Kebangsaan Malaysia for supporting this study through the Modal Insan fellowship (RFA1). Authors also extend their appreciation to The University Researchers Supporting Project Number (TURSP-2020/264), Taif Uni-versity, Taif, Saudi Arabia.

Conflicts of Interest: The authors declare no conflict of interest.

\section{References}

1. You, B.; Sun, Y. Innovative strategies for electrocatalytic water splitting. Acc. Chem. Res. 2018, 51, 1571-1580. [CrossRef]

2. Pal, G.; Rai, P.; Pandey, A. Chapter 1-Green synthesis of nanoparticles: A greener approach for a cleaner future. In Green Synthesis, Characterization and Applications of Nanoparticles; Shukla, A.K., Iravani, S., Eds.; Elsevier: Amsterdam, The Netherlands, 2019; pp. 1-26. [CrossRef]

3. Jadoun, S.; Arif, R.; Jangid, N.K.; Meena, R.K. Green synthesis of nanoparticles using plant extracts: A review. Environ. Chem. Lett. 2021, 19, 355-374. [CrossRef]

4. Shafey, A.M.E. Green synthesis of metal and metal oxide nanoparticles from plant leaf extracts and their applications: A review. Green Process. Synth. 2020, 9, 304-339. [CrossRef]

5. Singh, J.; Dutta, T.; Kim, K.-H.; Rawat, M.; Samddar, P.; Kumar, P. 'Green' synthesis of metals and their oxide nanoparticles: Applications for environmental remediation. J. Nanobiotechnol. 2018, 16, 84. [CrossRef]

6. Madkour, M.; Bumajdad, A.; Al-Sagheer, F. To what extent do polymeric stabilizers affect nanoparticles characteristics? Adv. Colloid Interface Sci. 2019, 270, 38-53. [CrossRef]

7. Tippayawat, P.; Phromviyo, N.; Boueroy, P.; Chompoosor, A. Green synthesis of silver nanoparticles in aloe vera plant extract prepared by a hydrothermal method and their synergistic antibacterial activity. PeerJ 2016, 4, e2589. [CrossRef]

8. Quispe, C.; Villalobos, M.; Bórquez, J.; Simirgiotis, M. Chemical composition and antioxidant activity of Aloe vera from the Pica Oasis (Tarapacá, Chile) by UHPLC-Q/Orbitrap/MS/MS. J. Chem. 2018, 2018, 6123850. [CrossRef] 
9. Phang, Y.-K.; Aminuzzaman, M.; Akhtaruzzaman, M.; Muhammad, G.; Ogawa, S.; Watanabe, A.; Tey, L.-H. Green synthesis and characterization of $\mathrm{CuO}$ nanoparticles derived from papaya peel extract for the photocatalytic degradation of palm oil mill effluent (POME). Sustainability 2021, 13, 796. [CrossRef]

10. Hendra, R.; Masdeatresa, L.; Abdulah, R.; Haryani, Y. Red dragon peel (Hylocereus polyrhizus) as antioxidant source. AIP Conf. Proc. 2020, 2243, 030007. [CrossRef]

11. Manigandan, R.; Dhanasekaran, T.; Padmanaban, A.; Giribabu, K.; Suresh, R.; Narayanan, V. Bifunctional hexagonal Ni/NiO nanostructures: Influence of the core-shell phase on magnetism, electrochemical sensing of serotonin, and catalytic reduction of 4-nitrophenol. Nanoscale Adv. 2019, 1, 1531-1540. [CrossRef]

12. Sekar, S.; Kim, D.Y.; Lee, S. Excellent oxygen evolution reaction of activated carbon-anchored NiO nanotablets prepared by green routes. Nanomaterials 2020, 10, 1382. [CrossRef]

13. Munna, F.T.; Selvanathan, V.; Sobayel, K.; Muhammad, G.; Asim, N.; Amin, N.; Sopian, K.; Akhtaruzzaman, M. Diluted chemical bath deposition of CdZnS as prospective buffer layer in CIGS solar cell. Ceram. Int. 2021, 47, 11003-11009. [CrossRef]

14. Tripathi, R.M.; Bhadwal, A.S.; Gupta, R.K.; Singh, P.; Shrivastav, A.; Shrivastav, B.R. ZnO nanoflowers: Novel biogenic synthesis and enhanced photocatalytic activity. J. Photochem. Photobiol. B Biol. 2014, 141, 288-295. [CrossRef]

15. Lamba, P.; Singh, P.; Singh, P.; Kumar, A.; Singh, P.; Bharti; Kumar, Y.; Gupta, M. Bioinspired synthesis of nickel oxide nanoparticles as electrode material for supercapacitor applications. Ionics 2021, 27, 5263-5276. [CrossRef]

16. Cao, Y.; Hu, P.; Jia, D. Solvothermal synthesis, growth mechanism, and photoluminescence property of sub-micrometer PbS anisotropic structures. Nanoscale Res. Lett. 2012, 7, 668. [CrossRef]

17. Talluri, B.; Prasad, E.; Thomas, T. Ultra-small $(\mathrm{r}<2 \mathrm{~nm})$, stable ( $>1$ year) copper oxide quantum dots with wide band gap. Superlattices Microstruct. 2018, 113, 600-607. [CrossRef]

18. Selvanathan, V.; Aminuzzaman, M.; Tey, L.-H.; Razali, S.A.; Althubeiti, K.; Alkhammash, H.I.; Guha, S.K.; Ogawa, S.; Watanabe, A.; Shahiduzzaman, M.; et al. Muntingia calabura leaves mediated green synthesis of CuO nanorods: Exploiting phytochemicals for unique morphology. Materials 2021, 14, 6379. [CrossRef]

19. Liang, Q.; Brocks, G.; Bieberle-Hütter, A. Oxygen evolution reaction (OER) mechanism under alkaline and acidic conditions. J. Phys. Energy 2021, 3, 026001. [CrossRef]

20. Jin, H.; Wang, X.; Tang, C.; Vasileff, A.; Li, L.; Slattery, A.; Qiao, S.-Z. Stable and highly efficient hydrogen evolution from seawater enabled by an unsaturated nickel surface nitride. Adv. Mater. 2021, 33, 2007508. [CrossRef]

21. Wang, C.; Qi, L. Hollow nanosheet arrays assembled by ultrafine ruthenium-cobalt phosphide nanocrystals for exceptional pH-universal hydrogen evolution. ACS Mater. Lett. 2021, 3, 1695-1701. [CrossRef]

22. Rani, B.J.; Ravi, G.; Yuvakkumar, R.; Ravichandran, S.; Ameen, F.; Al-Sabri, A. Efficient, highly stable Zn-doped NiO nanocluster electrocatalysts for electrochemical water splitting applications. J. Sol-Gel Sci. Technol. 2019, 89, 500-510. [CrossRef]

23. Zhu, K.; Shi, F.; Zhu, X.; Yang, W. The roles of oxygen vacancies in electrocatalytic oxygen evolution reaction. Nano Energy 2020, 73, 104761. [CrossRef]

24. Wang, Y.; Liang, Z.; Zheng, H.; Cao, R. Recent progress on defect-rich transition metal oxides and their energy-related applications. Chemistry 2020, 15, 3717-3736. [CrossRef]

25. Wang, H.; Xie, A.; Li, X.; Wang, Q.; Zhang, W.; Zhu, Z.; Wei, J.; Chen, D.; Peng, Y.; Luo, S. Three-dimensional petal-like graphene Co3.0Cu1.0 metal organic framework for oxygen evolution reaction. J. Alloys Comp. 2021, 884, 161144. [CrossRef]

26. Santos, H.L.S.; Corradini, P.G.; Medina, M.; Dias, J.A.; Mascaro, L.H. NiMo-NiCu Inexpensive Composite with High Activity for Hydrogen Evolution Reaction. ACS Appl. Mater. Interfaces 2020, 12, 17492-17501. [CrossRef]

27. Selvanathan, V.; Ruslan, M.H.; Aminuzzaman, M.; Muhammad, G.; Amin, N.; Sopian, K.; Akhtaruzzaman, M. ResorcinolFormaldehyde (RF) as a Novel Plasticizer for Starch-Based Solid Biopolymer Electrolyte. Polymers 2020, 12, 2170. [CrossRef]

28. Akbayrak, M.; Önal, A.M. Metal oxides supported cobalt nanoparticles: Active electrocatalysts for oxygen evolution reaction. Electrochim. Acta 2021, 393, 139053. [CrossRef] 